\title{
Vertical migration by bulk phytoplankton can sustain high primary productivity in the global ocean
}

\author{
PROF. KAI W WIRTZ ${ }^{1}$, LAN S SMITH ${ }^{2}$, MORITZ \\ MATHIS $^{1}$ AND JAN TAUCHER ${ }^{3}$
}

${ }^{1}$ Helmholtz Zentrum Geesthacht

${ }^{2}$ Research and Development Center for Global Change, JAMSTEC

${ }^{3}$ GEOMAR Helmholtz Centre for Ocean Research

Presenting Author: kai.wirtz@hzg.de

Net Primary Productivity (NPP) in the global ocean is commonly estimated in the range 50-60 $\mathrm{Pg}-\mathrm{C} / \mathrm{yr}$, which is comparable to the range of global NPP by terrestrial vegetation. High marine productivity is remarkable because of the unfavorable conditions for autotrophs in the surface ocean, where usually a gap of $50-150 \mathrm{~m}$ separates the zones where either light or nutrients reach sufficient levels. It has recently been suggested that the substantial fraction of motile phytoplankton can bridge these two distant niches through continuous down-- and upward migration.

We show that a Lagrangian growth model of vertically migrating phytoplankton can reproduce extensive data from various longterm monitoring stations, with focus on vertical profiles of NPP and Chlorophyll-a. The model further calculates the global rate of biological nutrient pumping and the concomitant enhancement of global marine NPP. Our results indicate a significant (30$50 \%$ ) contribution of biologically pumped nutrients to fuel new production and demonstrate that $56 \mathrm{Pg}-\mathrm{C} / \mathrm{yr}$ is a lower limit for oceanic NPP. The findings suggest that vertical migration by phytoplankton act as a strong driver of marine biogeochemistry and thus necessitates consideration of this process in the global carbon budget and in related modeling activities. Driven by changed stratification and mixed layer depths in a RCP8.5 Climate Change scenario simulation, our model projects higher NPP under future conditions, which contradicts widespread expectations.

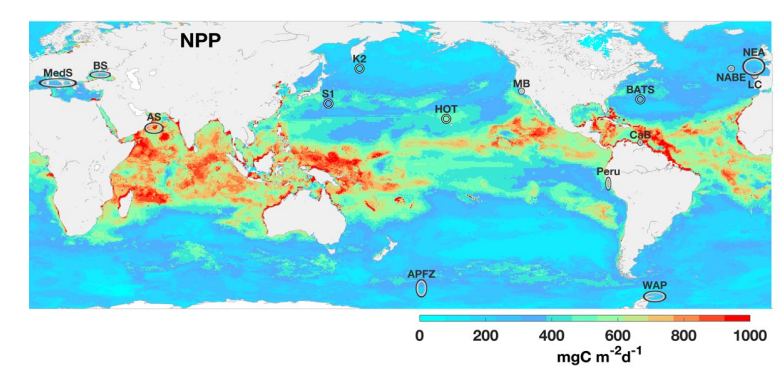

